\title{
Explantation of a 44-year-old Starr-Edwards mitral valve for delayed hemolysis
}

\author{
Joss Fernandez, MD, and Robert Saeid Farivar, MD, PhD, Iowa City, Iowa
}

\section{CLINICAL SUMMARY}

A 68-year-old woman was admitted 44 years after undergoing mitral valve replacement with a Starr-Edwards (SE) prosthesis (Edwards Lifesciences, Irvine, Calif) for rheumatic mitral valve stenosis. Since implantation of the prosthesis in 1965 via thoracotomy, the patient had done well and maintained her anticoagulation with warfarin sodium (Coumadin). She now had fatigue and anemia. Of note, 2 years earlier the patient had had third-degree heart block necessitating the implantation of a dual-chamber pacemaker. A full workup including upper and lower endoscopy did not reveal a source of bleeding. Hematologic testing showed decreased haptoglobin, a high lactic dehydrogenase value, and increased reticulocyte count, consistent with a hemolytic anemia. Bone marrow biopsy was performed, which showed erythroid hyperplasia, normocellular bone marrow, normal megakaryocytes, and absent iron, indicative of iron deficiency anemia. Despite iron replacement therapy she continued to become increasingly transfusion dependent. She received 9 units of blood in 1 month alone. Echocardiogram revealed normal prosthetic mitral valve function with a mitral valve mean gradient of $6 \mathrm{~mm} \mathrm{Hg}$, a severely calcified aortic valve with an aortic valve mean gradient of $58 \mathrm{~mm} \mathrm{Hg}$, and an aortic valve area of less than $1.0 \mathrm{~cm}^{2}$.

Aortic and mitral valve replacements were performed with bioprosthetic valves. Reoperative median sternotomy was performed. After standard cannulation, Sondergaard's groove was used to expose the mitral valve. The SE valve was in good condition without paravalvar leak. The mitral valve was explanted. The SE ball and cage were undamaged (Figure 1). There was no evidence of cloth tears or pannus overgrowth. The color of the ball had changed, presumably from lipid infiltration, but the ball was otherwise without pitting or defects. The patient underwent successful aortic valve replacement with a 21-mm Edwards Magna Thermafix bovine pericardial valve (Edwards) and mitral valve replacement with a 25-mm St Jude Epic porcine valve (St Jude Medical, Inc, St Paul, Minn). The patient was discharged

\footnotetext{
From the University of Iowa Hospitals and Clinics, Carver College of Medicine, Iowa City, Iowa.

Disclosures: None.

Received for publication Oct 28, 2009; accepted for publication Nov 6, 2009; available ahead of print Feb 1, 2010.

Address for reprints: Robert Saeid Farivar, MD, PhD, University of Iowa Hospitals and Clinics, Carver College of Medicine, 200 Hawkins Dr, SE 517GH, Iowa

City, IA 52242 (E-mail: robert-farivar@uiowa.edu).

J Thorac Cardiovasc Surg 2010;140:e35-6

$0022-5223 / \$ 36.00$

Copyright (c) 2010 by The American Association for Thoracic Surgery doi:10.1016/j.jtcvs.2009.11.011
}

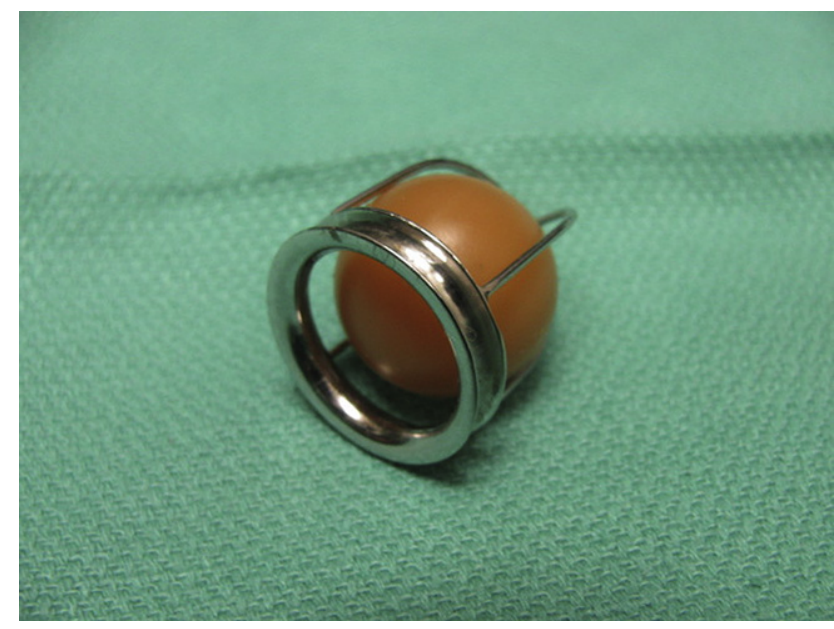

FIGURE 1. Starr-Edwards 44-year-old explanted mitral valve, model 6120 , with sewing ring removed. Valve is intact, with yellowing of ball.

on postoperative day 7. One month's follow-up demonstrated resolution of her hemolytic anemia, with an increase in hematocrit value from $29 \%$ to $38 \%$ without transfusion.

\section{DISCUSSION}

Native aortic valve stenosis alone has rarely been associated with hemolysis, ${ }^{1}$ although gradients exceeding $50 \mathrm{~mm} \mathrm{Hg}$ have been shown to cause mechanical hemolysis. ${ }^{2}$ The turbulence associated with the combination of a mechanical mitral valve and aortic stenosis has previously been implicated as a cause of hemolysis. ${ }^{3}$ We believe that this combination resulted in hemolytic anemia in this patient, inasmuch as the onset of hemolysis coincided with worsening of aortic stenosis. This resolved after aortic and mitral valve rereplacement.

Developed by engineer Miles Edwards and Dr Albert Starr, the SE valve was first successfully implanted on Sept 21, 1960. Since then, more than 250,000 patients have received the valve. The model $6120 \mathrm{SE}$ mitral valve prosthesis used in this patient was introduced in 1965 with cloth-covered sewing rings and bare-metal struts. This dramatically reduced the incidence of thromboembolism from the previous generation of the valve, but wear of the valve cloth caused hemolysis. In our patient, the ball was in remarkably good condition; thus pitting was not a cause of hemolysis. Late hemolysis has been previously reported up to 25 years after mitral valve replacement. The duration of survival to explantation is also remarkable. Others have reported explantation of the SE aortic valve 33 years after implantation ${ }^{4}$ and of the SE mitral prosthetic valve 31 years after implantation..$^{5}$ There is also a report of a 40 -year survival of a patient with an SE valve in the mitral position. ${ }^{6}$ 
The current patient is, to our knowledge, the oldest reported to undergo explantation of an SE valve, and the duration of implantation is the longest reported. The case demonstrates the efficacy and safety of double valve replacement for delayed hemolysis in a mechanical valve, even in patients in whom the valve has been seated for more than 4 decades.

\section{References}

1. Kawase I, Matsuo T, Sasayama K, Suzuki H, Nishikawa H. Hemolytic anemia with aortic stenosis resolved by urgent aortic valve replacement. Ann Thorac Surg. 2008;86:645-6.
2. Jacobson RJ, Rath CE, Perloff JK. Intravascular haemolysis and thrombocytopenia in left ventricular outflow obstruction. Br Heart J. 1973;35:849-54.

3. Konstantopoulos K, Kasparian T, Sideris J, Voskaridou E, Loukopoulos D. Mechanical hemolysis associated with a bioprosthetic mitral valve combined with a calcified aortic valve stenosis. Acta Haematol. 1994;91:164-5.

4. Misumi T, Kudo M, Koizumi K, Kumamaru H. Reoperation for a Starr-Edwards aortic prosthetic valve 33 years after initial implantation. Jpn J Thorac Cardiovasc Surg. 2005;53:165-8.

5. Goshima M, Shiono M, Yamamoto T, Inoue T, Hata M, Sezai A, et al. [Reoperation for a Starr-Edwards ball valve prosthesis implanted in mitral position 31 years ago] [In Japanese]. Kyobu Geka. 2003;56:535-40.

6. Suezawa T, Morimoto T, Jinno T, Tago M. Forty-year survival with SmeloffCutter and Starr-Edwards prostheses. Ann Thorac Surg. 2008;85:e14-6.

\title{
Two cases of aneurysm of the anterior mitral valve leaflet associated with transcatheter aortic valve endocarditis: A mere coincidence?
}

\author{
Nicolo Piazza, MD, FRCPC, ${ }^{\text {a }}$ Sebastanio Marra, MD, ${ }^{\mathrm{b}}$ John Webb, MD, ${ }^{\mathrm{c}}$ Maurizio D'Amico, MD, \\ Mauro Rinaldi, MD, ${ }^{\mathrm{b}}$ Massimo Boffini, MD, ${ }^{\mathrm{d}}$ Chiara Comoglio, MD, ${ }^{\mathrm{d}}$ Paolo Scacciatella, MD, ${ }^{\mathrm{c}}$ \\ Arie-Pieter Kappetein, MD, PhD, ${ }^{\mathrm{e}}$ Peter de Jaegere, $\mathrm{MD}, \mathrm{PhD},{ }^{\mathrm{a}}$ and Patrick W. Serruys, MD, PhD, ${ }^{\mathrm{a}}$ \\ Rotterdam, The Netherlands, Turin, Italy, and Vancouver, British Columbia, Canada
}

The incidence of transcatheter aortic valve endocarditis (TAVE) is currently unknown. To the best of our knowledge, 2 clinical case reports of TAVE have been published (1 Edwards SAPIEN [Edwards Lifesciences, Irvine, Calif] and 1 Medtronic CoreValve ReValving System [Medtronic CV, Luxembourg Sarl]). ${ }^{1,2}$ Interestingly, both cases were associated with aneurysm and perforation of the anterior mitral valve leaflet - a link that has not been previously reported. We briefly review the clinical presentations of these cases and discuss the possible implications of endocarditis in the context of transcatheter aortic valve implantation.

\section{CLINICAL SUMMARIES \\ Patient 1}

CoreValve ReValving System (Figure 1, $A$ and $B$ ). Comoglio and associates ${ }^{1}$ reported a case of TAVE in a 66-year-old man who underwent transfemoral aortic valve

\footnotetext{
From the Division of Cardiology, ${ }^{a}$ Erasmus MC, Thoraxcenter, Rotterdam, The Netherlands; the Division of Cardiology, ${ }^{\mathrm{b}}$ University of Turin, San Giovanni Battista Hospital, Turin, Italy; the Division of Cardiology, ${ }^{\mathrm{c}}$ St Paul's Hospital, Vancouver, British Columbia, Canada; the Division of Cardiac Surgery, ${ }^{\mathrm{d}}$ University of Turin, San Giovanni Battista Hospital, Turin, Italy; and the Division of Cardiac Surgery, Erasmus MC, Thoraxcenter, Rotterdam, The Netherlands.

Disclosures: None.

Received for publication Nov 1, 2009; accepted for publication Nov 6, 2009; available ahead of print Feb 18, 2010.

Address for reprints: Patrick W. Serruys, MD, PhD, FACC, Ba 583, Thoraxcenter, Erasmus Medical Center, Molewaterplein 40, 3015 GD, Rotterdam, The Netherlands (E-mail: p.w.j.c.serruys@erasmusmc.nl).

J Thorac Cardiovasc Surg 2010;140:e36-8

$0022-5223 / \$ 36.00$

Copyright (c) 2010 by The American Association for Thoracic Surgery doi:10.1016/j.jtcvs.2009.11.012
}

implantation with the CoreValve ReValving System. The prosthesis was positioned too low into the left ventricular outflow tract, resulting in moderate paravalvular aortic regurgitation. After postimplant balloon dilatation, the aortic regurgitation was reduced to a mild-moderate degree. The postoperative course was complicated by ventricular arrhythmias of unknown etiology. One month after the procedure, the patient was readmitted with heart failure and recurrent ventricular arrhythmias. Echocardiography revealed moderate paravalvular aortic regurgitation, preserved left ventricular function, but progressive left ventricular dilatation. Three months after implantation, the patient had fever and blood cultures positive for Corynebacterium. Transesophageal echocardiography showed severe mitral regurgitation resulting from a perforated aneurysm of the anterior mitral valve leaflet at the level of the ventricular edge of the metal frame. The patient underwent surgical aortic valve replacement with a 23-mm Carpentier-Edwards bioprosthetic valve (Edwards) and pericardial patch repair of the anterior mitral valve leaflet. In addition to a vegetative lesion observed on the transcatheter aortic valve cusp, the left main coronary artery ostium was obstructed by a strut of the CoreValve frame. The postoperative course was uneventful and the patient was discharged on postoperative day 7 .

\section{Patient 2}

Edwards SAPIEN prosthetic heart valve (Figure 1, C and $D)$. Wong and associates ${ }^{2}$ reported a case of TAVE in an 88-year-old man who underwent transfemoral aortic valve implantation with a 26-mm Edwards SAPIEN 